\title{
Nutritional Quality, Potential Health Promoting Properties and Sensory Perception of an Improved Gluten-Free Bread Formulation Containing Inulin, Rice Protein and Bioactive Compounds Extracted from Coffee Byproducts
}

\author{
Alessandro Guglielmetti ${ }^{1}$, Beatriz Fernandez-Gomez ${ }^{2}$, Giuseppe Zeppa ${ }^{1}$, Maria Dolores del Castillo ${ }^{2, *}$ \\ ${ }^{1}$ Department of Agricultural, Forest and Food Sciences (DiSAFA), University of Turin, Grugliasco, Torino, 10095, Italy \\ ${ }^{2}$ Department of Food Analysis and Bioactivity, Institute of Food Science Research (CIAL, CSIC-UAM), \\ C/ Nicolás Cabrera 9, Campus de la Universidad Autónoma de Madrid, Madrid 28049, Spain
}

Key words: $\alpha$-glucosidase, sugars bioaccesibility, coffee by-products, inulin, antioxidant coffee fibre, gluten-free bread

The present study aimed to improve the formulation of a gluten-free commercial bread-making premix by adding inulin, rice protein and extracts of coffee by-products (silverskin and husk) to obtain healthier products enriched in protein and dietary fiber with the potential to reduce the risk of chronic diseases. The new formulation combines well-known and novel food ingredients. To validate the novel ingredients, we determined the physicochemical characterization, caffeine and chlorogenic acid contents, and food safety of coffee silverskin (CSE) and husk (CHE) extracts. Sensory and nutritional quality, bioactive compounds (chlorogenic acid, total phenolic compounds, melanoidins and browning), in vitro bioaccessibility, and health-promoting properties (overall antioxidant capacity and $\alpha$-glucosidase activity) of the breads were evaluated as well.

Results support the feasibility of CSE and CHE as natural sustainable sources of antioxidants, $\alpha$-glucosidase inhibitors and colorants. The observed health-promoting properties suggest that coffee by-product extracts could potentially be used as functional food ingredients or supplements to reduce the risk of chronic diseases associated with oxidative stress and to control postprandial glucose levels. Based on consumers' preferences, we obtained new bread formulations with a high nutritional and sensorial quality, suitable for celiacs and with the potential to reduce the risk of gastrointestinal disease related to oxidative stress. Data on in vitro digestion indicated a significant $(\mathrm{p}<0.05)$ decrease in the bioaccessibility of sugars and a significant increase $(\mathrm{p}<0.05)$ in antioxidants.

\section{ABBREVIATIONS}

$\mathrm{CD}$, celiac disease; CGA, chlorogenic acid; CHE: coffee husk extract; CR, commercial recipe; CSE, coffee silverskin extract; GI, glycaemic index; IDF, insoluble dietary fibre; NF, new formulation; NFS, new formulation with $25 \mathrm{~g} \mathrm{CSE} / \mathrm{kg}$ dry matter CSE; NFH, new formulation with $25 \mathrm{~g} \mathrm{CHE} / \mathrm{kg}$ dry matter; OTA, Ochratoxin A; SDF, soluble dietary fibre; TAC, total antioxidant capacity; T2D, type 2 diabetes, TDF, total dietary fibre; TPC, total phenolic compounds.

\section{INTRODUCTION}

Gluten-free products present a major challenge for the food industry in terms of organoleptic, technological and nutritional characteristics [Conte et al., 2019]. Among gluten-free foods, bread is the most consumed in Europe [Padalino et al., 2016]. The absence of gluten in these products affects starch digestibility increasing the postprandial glycaemic response. Consequently, people on a gluten-free diet have a higher risk of suffering from chronic diseases

\footnotetext{
* Corresponding Author: Tel.: +34 910017953; Fax: 0034910017905;

E-mail: mdolores.delcastillo@csic.es (M.D. del Castillo)
}

like type 2 diabetes (T2D) [Giuberti et al., 2015]. However, the addition of dietary fibre and protein has been found to reduce the glycaemic response of gluten-free products such as bread [Scazzina et al., 2015].

Coffee husk is the outer skin and pulp obtained from the wet processing of coffee berries [del Castillo et al., 2019]. It has a high content of carbohydrates $(35-85 \%)$, soluble fibers $(30.8 \%)$, minerals $(3-11 \%)$, and proteins $(5-11 \%)$. It is also rich in insoluble dietary fiber and can be a source of phytochemicals such as tannins (5-9\%) and cyanidins (20\%) for the food industries [del Castillo et al., 2019].

Coffee silverskin is a thin tegument of the outer layer of the two beans forming the green coffee seed and represents $4.2 \%(\mathrm{w} / \mathrm{w})$ of the coffee cherry. It is obtained when green coffee beans are roasting, being the unique byproduct of the roasting process. Coffee silverskin has high contents of dietary fiber (68-80\%) and polysaccharides (60-70\%), and presents a very high antioxidant activity [Pourfarzad et al., 2013; Bresciani et al., 2014]. Prior studies have proposed the use of coffee silverskin as an innovative food ingredient [Ballesteros et al., 2014; Bresciani et al., 2014].

The aqueous extracts of coffee silverskin (CSE) and coffee husk (CHE) have recently been proposed as a source of two safe food ingredients: aqueous extracts enriched in phyto- 
chemicals and antioxidant dietary fiber [Iriondo-DeHond et al., 2018]. CSE was used in the preparation of biscuits with no added sugar, obtaining a product with a good nutritional quality and improved texture and colour [Garcia-Serna et al., 2014]. Besides, CSE can be used to prevent or treat age-related chronic diseases caused by oxidation and inflammation, such as T2D. The bioactive compounds present in CSE affect several pathways involved in the pathogenesis of T2D, thereby reducing the risk of this disease [del Castillo et al., 2016].

This study aimed to evaluate the use of CSE and CHE as functional ingredients in the formulation of gluten-free breads with a high nutritional value and the potential to control postprandial glucose. To the best of our knowledge, the use of CHE for diabetes has not been previously reported.

\section{MATERIALS AND METHODS}

\section{Reagents}

The reagents used in this study were: intestinal acetone powders, 4-methylumbelliferyl $\alpha$-D-glucopyranoside (4-MUG), acarbose, $\alpha$-amylase from human saliva (type IX-A), porcine pepsin from gastric mucosa (3200-4500 U/mg protein), pancreatin from porcine pancreas, porcine bile extract, cholestyramine resin, chlorogenic acid (CGA), caffeine, phloroglucinol, salicylic acid; 2,2'-azinobis [3-ethylbenzothiazoline-6-sulphonic acid] (ABTS), Folin-Ciocalteu reagent, Na-Acetyl-L-lysine, ortho-phthalaldehyde (OPA), methanol HPLC-grade, phenol, concentrated sulphuric acid (93-98\%), and ammonium chloride were from Sigma-Aldrich (St. Louis, MO, USA). Sucrose, D-fructose, D-glucose kit, and the dietary fibre kit were from Megazyme (International Ireland Ltd, Bray, Ireland).

Buffered peptone water (BPW) was from Biocult, BD ${ }^{\mathrm{Tm}}$ Difco $^{\mathrm{TM}}$ plate count agar (PCA) medium and brain $\mathrm{BD}^{\mathrm{TM}}$ Bacto $^{\text {TM }}$ heart infusion (BHI) agar from BD (New York, NJ, USA) and Sabouraud dextrose agar (SDA) with chloramphenicol from CONDA (Torrejón de Ardoz, Madrid, Spain). Water was purified using a Milli-Q and Elix system (Millipore, Molsheim, France). All other chemicals and reagents were of analytical grade.

\section{Apparatus}

Microplate spectrometers BioTek powerWaveTM XS (BioTek Instruments, Winooski, VT, USA) and FP-6200 (JASCO, Easton, MD, USA) were used for the spectrophotometric assays. Bloc-digest 12 (Selecta, Barcelona, Spain) was employed for the digestion process in the Kjeldahl method. Accela liquid chromatograph (Thermo Scientific, San Jose, CA, USA) equipped with a DAD and coupled to a TSQ Quantum (Thermo Scientific) triple quadrupole analyser via an electrospray ionisation (ESI) interface was used to determine caffeine and CGA content. CertoCLAV A-4050 autoclave (CertoCLAV, Traun, Austria), Stomacher ${ }^{\circledR} 400$ Circulator (Seward, UK), horizontal laminar flow bench Mini-H (Telstar, Madrid, Spain), Nüve EN120 incubator (Nüve, Ankara, Turkey) and SANYO Mir154 incubator (SANYO Electric Biomedical Co., Ltd., Osaka, Japan) were used for microbiological analysis. Bread was made using a PAN 850 bread machine (Fagor, San Sebastián, Spain).

\section{Commercial food ingredients}

Bread was prepared using a gluten-free commercial baking pre-mix. The composition of the pre-mix was: $753 \mathrm{~g} / \mathrm{kg}$ of corn starch, $52 \mathrm{~g} / \mathrm{kg}$ of dietary fibre, $20 \mathrm{~g} / \mathrm{kg}$ of salt, $13 \mathrm{~g} / \mathrm{kg}$ of fat, and $10 \mathrm{~g} / \mathrm{kg}$ of protein. ORAFTI ${ }^{\circledR}$ inulin and Remypro $\mathrm{N} 80+$ rice protein from Beneo Ibérica (Barcelona, Spain) were used to fortify the breads.

\section{Coffee by-products ingredients}

Arabica coffee husk (Coffea arabica) was provided by Delikia (Pontevedra, Spain) while Robusta coffee silverskin (Coffea canephora) was provided by Fortaleza S.A. (Vitoria, Spain). Raw materials were stored at room temperature in a dry and dark place until the preparation of extracts.

\section{Aqueous coffee byproduct extracts}

Robusta CSE and Arabica CHE aqueous extracts were obtained with hot water $(50 \mathrm{~g} / \mathrm{L})$ at $100^{\circ} \mathrm{C}$ for $10 \mathrm{~min}$ as described in the patent WO 2013/004873 [delCastillo et al., 2013]. Extracts were freeze-dried and stored at $-20^{\circ} \mathrm{C}$ until use.

\section{Microbiological analyses of CSE and CHE}

The safety of coffee byproduct extracts as food ingredients was evaluated by assaying counts of: (1) total aerobic microorganisms, (2) aerobic microorganisms forming endospores, and (3) moulds and yeasts. All assays were performed in sterile conditions with previous solubilization of the samples $(10 \mathrm{~g})$ in BPW (90 mL) using a stomacher (230 rpm, $1 \mathrm{~min})$. Different conditions were set for each analysis: (1) pour plate method, PCA medium, incubation at $30^{\circ} \mathrm{C} 72 \mathrm{~h}$; (2) pour plate, BHI agar medium, preincubation $\left(80^{\circ} \mathrm{C}, 10 \mathrm{~min}\right)$ and incubation at $37^{\circ} \mathrm{C} 48 \mathrm{~h}$; and and (3) spread method, SDA with chloramphenicol and incubation at $25^{\circ} \mathrm{C} 120 \mathrm{~h}$. Results were expressed as colony-forming units per gram $(\mathrm{CFU} / \mathrm{g})$.

\section{Physicochemical analyses of CSE and CHE}

For the analyses, each freeze-dried extract $(250 \mathrm{mg})$ was dissolved in Milli-Q water ( $10 \mathrm{~mL}$ ) for $5 \mathrm{~min}$ using a vortex mixer at room temperature and then centrifuged at $4,000 \times g$ for $10 \mathrm{~min}$. The supernatants were filtered through a $13 \mathrm{~mm}$ PTFE filter (pore size $0.45 \mu \mathrm{m}$ ). Samples were kept at $-20^{\circ} \mathrm{C}$ until analysis. The following components of CSE and CHE were analyzed: browning, content of total carbohydrates, glycemic sugars, total proteins, total dietary fibre (TDF), total lipids, total phenolic compounds (TPC), CGA and caffeine content, melanoidins, total antioxidant capacity (TAC), and $\alpha$-glucosidase activity.

\section{Bread-making}

The studied bread formulations are shown in Table 1. Control breads were prepared using a gluten-free baking premix (commercial recipe, CR) following the manufacturer's instructions. To reduce the bioaccessibility of sugars and increase the nutritional value of the commercial preparation, new bread formulations (NF) containing inulin and rice protein with no sugar were proposed. These basic formulations were supplemented with $25 \mathrm{~g}$ of CSE per kg of dry matter (d.m.) (NFS) or $25 \mathrm{~g}$ of CHE per kg d.m. (NFH). The breads were made with a domestic bread-maker using the gluten-free programme, obtaining $1000 \mathrm{~g}$ of the product. 
TABLE 1. Bread formulations.

\begin{tabular}{lcc|cc}
\hline Ingredients (g) & CR & NF & NFS & NFH \\
\hline Gluten-free baking pre-mix & 410 & 385 & 372 & 372 \\
Sourdough & 20 & 13 & 13 & 13 \\
Sunflower oil & 90 & 19 & 19 & 19 \\
Sugar & 40 & 0 & 0 & 0 \\
Rice protein & 0 & 55 & 55 & 55 \\
Inulin & 0 & 40 & 40 & 40 \\
CSE & 0 & 0 & 13 & 0 \\
CHE & 0 & 0 & 0 & 13 \\
Water & 240 & 500 & 500 & 500 \\
\hline $\begin{array}{l}\text { Estimated calories } \\
\text { (kcal/100 g bread) }\end{array}$ & 241 & 180 & 178 & 177 \\
$\begin{array}{l}\text { Estimated protein energy value } \\
\text { (\% on total kcal) }\end{array}$ & 1.2 & $26.2^{\ddagger}$ & $26.5^{\ddagger}$ & $26.6^{\ddagger}$ \\
$\begin{array}{l}\text { Estimated fibre content } \\
\text { (g fibre/100 g bread) }\end{array}$ & $3.8^{*}$ & $11.7 \phi$ & $11.6^{\phi}$ & $11.6^{\phi}$ \\
\hline
\end{tabular}

$\mathrm{CR}$ - commercial recipe; NF - new formulation; NFS - new formulation with $25 \mathrm{~g}$ of coffee silverskin extract (CSE) $/ \mathrm{kg} \mathrm{d.m}$.; NFH - new formulation with $25 \mathrm{~g}$ of coffee husk extract (CHE)/ kg d.m.

*CR might be "source of fibre" ( $\geq 3 \mathrm{~g}$ fibre/100 g bread); $\ddagger$ NF, NFS and NFH might be "high in protein" ( $\geq 20 \%$ energy value of bread provided by protein); $\$$ NF, NFS and NFH might be "high fibre content" ( $\geq 6 \mathrm{~g}$ fibre/100 g bread).

Homemade loaves were sliced (10 mm thick), and the slices were frozen and subsequently freeze-dried. The freeze-dried slices (approximately $50 \mathrm{~g}$ ) were ground and sieved through a 40-mesh screen to obtain a powder. For the analyses, the bread powder ( $1 \mathrm{~g})$ was dissolved in Milli-Q water $(10 \mathrm{~mL})$ for $5 \mathrm{~min}$ using a vortex mixer at room temperature and then centrifuged at $4,000 \times g$ for $10 \mathrm{~min}$. The supernatants were filtered through a $13 \mathrm{~mm}$ PTFE filter (pore size $0.45 \mu \mathrm{m}$ ). Samples were kept at $-20^{\circ} \mathrm{C}$ until analysis.

\section{Sensory analysis}

A preliminary sensory analysis of the NFS and NFH breads found that the maximum amount of CSE and CHE considered acceptable was $25 \mathrm{~g} / \mathrm{kg} \mathrm{d.m}$. (data not shown). A sensory analysis of NF bread was carried out to evaluate its acceptance and of NFS and NFH breads to estimate the influence of extract supplementation on their sensory perception. Colour, texture, taste, and overall acceptance were evaluated in a hedonic sensory test involving 30 untrained panellists. Results of the verbal scale test were converted to a 7-point scale from 1 (lowest) to 7 (highest). Breads were considered acceptable if the average of the panellists' scores for all the parameters was equal to or above 4 .

\section{Physicochemical analyses}

\section{Total carbohydrate content}

Total carbohydrate content was determined using the phenol-sulphuric method described by Masuko et al. [2005]. Samples $(0.1 \mathrm{~mL})$ were mixed with concentrated sulphuric acid (0.3 mL; 93-98\% purity) and phenol (0.09 mL; $50 \mathrm{~g} / \mathrm{L})$ in a glass flask. The mixtures were incubated at $90^{\circ} \mathrm{C}$ for $5 \mathrm{~min}$ and cooled at room temperature. Absorbance was measured at $490 \mathrm{~nm}$. A calibration curve was constructed using glucose $(0.1-0.85 \mathrm{~g} / \mathrm{L})$. Reagent blank and sample blank were also analysed in each set of samples. All measurements were performed in triplicate, and results were expressed as $\mathrm{g} / 100 \mathrm{~g}$.

\section{Glycaemic sugars}

Glucose, fructose, and sucrose contents were determined with a K-SUFRG kit (Megazyme) adapted to a microplate format following the manufacturer's instructions. Analysis was carried out in triplicate. Results were expressed as g/100 g.

\section{Dietary fiber}

Insoluble (IDF), soluble (SDF), and TDF contents were determined using an enzymatic-gravimetric assay based on the AOAC-991.43 [1995] and AACC-32.07.01 [1995] methods. Analysis was carried out in duplicate for each sample. Results were expressed as g/100 g.

\section{Total proteins}

Total protein content was determined following the Kjeldahl method [AOAC-920.87, 32.1.22, 1995]. This procedure was carried out in triplicate. Results were expressed as g/100 g.

\section{Free amino groups}

An OPA assay was carried out to determine free amino groups content [Michalska et al., 2008] in the soluble fraction of digested bread. Quantitative analysis was performed using a calibration curve of $\mathrm{N} \alpha$-acetyl-1-lysine $(0.01-1 \mathrm{mmol} / \mathrm{L})$. All measurements were performed in triplicate. Results were expressed as mg Lys eq./kg of digested bread.

\section{Total lipids}

Total lipid content was determined according to Toschi et al. [2014] with minor modifications. Briefly, the sample (1 g) was mixed with $50 \mathrm{~mL}$ of $n$-hexane, homogenized by Ultra-Turrax for $3 \mathrm{~min}$ and then subjected to ultrasound treatment for $20 \mathrm{~min}$. The organic layer (containing the lipid matter) was separated by centrifugation $(1,620 \times g$ for $20 \mathrm{~min}$ ). The lipid fraction was collected and dried in a rotary evaporator. The fat content was determined gravimetrically. The analysis was carried out in triplicate. Results were expressed as $\mathrm{g} / 100 \mathrm{~g}$.

\section{Total phenolic compounds}

TPC content in the samples was analyzed using FolinCiocalteu adapted to a micromethod [Contini et al., 2008]. The reaction was initiated by mixing $10 \mu \mathrm{L}$ of the sample with $150 \mu \mathrm{L}$ of the Folin-Ciocalteu reagent. After incubation at room temperature for $3 \mathrm{~min}, 50 \mu \mathrm{L}$ of sodium bicarbonate solution were added. The kinetics of the reaction at $37^{\circ} \mathrm{C}$ was followed for $120 \mathrm{~min}$ by measuring absorbance at $735 \mathrm{~nm}$ once each minute. Sample blank and reagent blank were also analyzed in each set of samples. The CGA calibration curve was used for quantification $(0.01-0.6 \mathrm{~g} / \mathrm{L})$. All measurements were performed in triplicate, and results were expressed as mg CGA eq./g freeze-dried sample. 


\section{Caffeine and CGA content}

Caffeine and CGA content were determined with UPLC-MS/MS as described by Fernandez-Gomez et al. [2016]. Samples were diluted with Milli-Q water. For CGA quantification, $50 \mu \mathrm{g} / \mathrm{mL}$ of phloroglucinol were added as an internal standard, and $50 \mu \mathrm{g} / \mathrm{mL}$ of salicylic acid as an internal standard for caffeine. All the analyses were performed in triplicate, and results were expressed as mg caffeine or $\mathrm{CGA} / \mathrm{g}$ freeze-dried sample.

\section{Browning}

Browning was measured at $405 \mathrm{~nm}$. All measurements were made in triplicate, and results were expressed as absorbance $(\mathrm{Abs}) / \mathrm{g}$ freeze-dried sample.

\section{Melanoidins}

Melanoidins content was determined according to Silván et al. [2010]. Samples were subjected to ultrafiltration using a Microcon YM-10 regenerated cellulose $10 \mathrm{kDa}$ (Millipore, Bedford, MA, USA) at $12,000 \times g$ for $10 \mathrm{~min}$. Melanoidins were measured spectrophotometrically at $405 \mathrm{~nm}$. The analysis was carried out in triplicate and results were expressed as absorbance (Abs)/g freeze-dried sample.

\section{Health-promoting properties of bread}

\section{Antioxidant capacity}

An indirect $\mathrm{ABTS}^{\cdot+}$ decolourisation assay was performed according to Oki et al. [2006]. An $\mathrm{ABTS}^{*+}$ stock solution was prepared by adding $44 \mu \mathrm{L}$ of potassium persulfate $(140 \mathrm{mmol} / \mathrm{L})$ to a $2.5 \mathrm{~mL} \mathrm{ABTS}^{+}$aqueous solution $(7 \mathrm{mmol} / \mathrm{L})$. The mixture was allowed to stand for $16 \mathrm{~h}$ at room temperature. The working solution of the radical $\mathrm{ABTS}^{+}$ was prepared by diluting the stock solution $1: 75(\mathrm{v} / \mathrm{v})$ in a sodium phosphate buffer $(5 \mathrm{mmol} / \mathrm{L}, \mathrm{pH}$ 7.4) to obtain an absorbance value of $0.7 \pm 0.02$ at $734 \mathrm{~nm}$. Samples $(30 \mu \mathrm{L})$ were added to $270 \mu \mathrm{L}$ of the working solution of ABTS ${ }^{*+}$ in a microplate. Absorbance was measured at $734 \mathrm{~nm}$ and $30^{\circ} \mathrm{C}$ for $18 \mathrm{~min}$, every $2 \mathrm{~min}$. The reaction was complete after $5 \mathrm{~min}$. CGA calibration $(0.15-2 \mathrm{mmol} / \mathrm{L})$ was used. All measurements were performed in triplicate. Results were expressed as $\mathrm{mg}$ CGA eq/g freeze-dried sample.

The antioxidant capacity of the insoluble fraction of the digested breads was determined by a direct $\mathrm{ABTS}^{-+}$assay or QUENCHER assay [Açar et al., 2009]. Briefly, $10 \mathrm{mg}$ of the sample were mixed with $70 \mathrm{mg}$ of cellulose and stirred. After that, $10 \mathrm{mg}$ of the mixture were mixed with $1.7 \mathrm{~mL}$ of the ABTS ${ }^{*+}$ solution in a thermomixer $\left(600 \mathrm{rpm}, 37^{\circ} \mathrm{C}, 5 \mathrm{~min}\right)$ and centrifuged $\left(4500 \times g, 25^{\circ} \mathrm{C}, 2 \mathrm{~min}\right)$. Absorbance $(734 \mathrm{~nm})$ of the supernatant was measured in a microplate. A CGA calibration curve $(0.01-0.25 \mathrm{~g} / \mathrm{L})$ was used. Measurements were performed in triplicate and results expressed as g CGA eq/ $100 \mathrm{~g}$.

\section{$\alpha$-Glucosidase activity}

Alpha-glucosidase activity was determined following Berthelot \& Delmotte [1999] with slight modifications. Briefly, $0.1 \mathrm{~g}$ of rat intestine powder was dissolved in $3 \mathrm{~mL}$ of $\mathrm{NaCl}$ $(90 \mathrm{~g} / \mathrm{L})$, sonicated in an ice bath for $6 \mathrm{~min}$ and then centrifuged at $10,000 \times g$ for 30 min to extract the enzyme contained in the supernatant. In a 96-well microplate, $100 \mu \mathrm{L}$ of the sample dissolved in phosphate buffered saline $(100 \mathrm{mmol} / \mathrm{L}, \mathrm{pH}$ 6.9) were mixed with $100 \mu \mathrm{L}$ of $\alpha$-glucosidase (diluted $1 / 10$ ) and $100 \mu \mathrm{L}$ of $4-\mathrm{MUG}(2 \mathrm{mmol} / \mathrm{L})$. Fluorescence was then monitored at an excitation wavelength of $360 \mathrm{~nm}$ and an emission wavelength of $460 \mathrm{~nm}$ at $37^{\circ} \mathrm{C}$ for $30 \mathrm{~min}$. Blank of sample and negative control (buffer, enzyme and 4-MUG) were included. Acarbose was used as a positive control of the inhibition of enzymatic activity. Curves of samples and acarbose were assayed to cover the whole range of inhibition of the enzyme $(\sim 0.5-96 \%)$. The percentage of $\alpha$-glucosidase inhibition was calculated using the equation: $\% \alpha$-glucosidase $=$ $\left[\left(\mathrm{F}_{\text {n.c. }} \mathrm{F}_{\mathrm{s}}\right) / \mathrm{F}_{\mathrm{n} . \mathrm{c}}\right] \times 100$, where $\mathrm{F}_{\text {n.c. }}$ is the fluorescence of the negative control (without inhibitor) and $F_{s}$ is the fluorescence of the sample. All measurements were performed in triplicate, and results were expressed as sample concentration $(\mathrm{g} / \mathrm{L})$ causing $50 \% \alpha$-glucosidase inhibition $\left(\mathrm{IC}_{50}\right)$.

\section{Release of nutrients and bioactive compounds during bread digestion}

Bioaccessibility of the nutrients and bioactive compounds composing the breads was estimated applying an in vitro oralgastrointestinal digestion system according to Hollebeeck et al. [2013] with minor modifications. One $\mathrm{g}$ of sample was digested as follows: salivary step (pH 6.9, $10 \mathrm{~mL}, 5 \mathrm{~min}, 3.9 \mathrm{U}$-amylase/ $\mathrm{mL}$, aerobic), gastric step (pH 2, $13 \mathrm{~mL}, 90 \mathrm{~min}, 71.2 \mathrm{U}$ pep$\sin / \mathrm{mL}$, aerobic), and duodenal step (pH 7, $16 \mathrm{~mL}, 150 \mathrm{~min}$, $9.2 \mathrm{mg}$ pancreatin and $55.2 \mathrm{mg}$ bile extract $/ \mathrm{mL}$, aerobic). The obtained digests were centrifuged $\left(1700 \times g, 4^{\circ} \mathrm{C}, 20 \mathrm{~min}\right)$ and separated into soluble and insoluble fractions. The soluble fraction was treated to mimic human intestinal reabsorption of bile salts with cholestyramine resin $(100 \mathrm{~g} / \mathrm{L})$ [MartinezSaez et al., 2017]. The soluble and insoluble fractions were freeze-dried and stored in a dry cold place until analysis.

The soluble fractions of the digested breads were analyzed for contents of glycemic sugars, free amino acids, TPC, CGA and caffeine content, TAC, and $\alpha$-glucosidase activity as described in the section of physicochemical analyses and healthpromoting properties of bread, respectively. The insoluble fraction was recovered, and its antioxidant capacity was analyzed by direct $\mathrm{ABTS}^{\cdot+}$ assay as described in the section of health-promoting properties of bread.

\section{Statistical analysis}

Data were expressed as mean \pm standard deviation. Statistical analyses were performed using Statistica 7.1 (Stat Software Inc., California, USA). Experimental data were analyzed using ANOVA and significant differences among means from triplicate analyses at $p \leq 0.05$ were determined using post hoc Duncan's test.

\section{RESULTS AND DISCUSSION}

\section{Validation of CSE and CHE as food ingredients}

\section{Food safety}

The microbiological analyses of CSE showed values of $3.25 \times 10^{5} \mathrm{CFU} / \mathrm{g}$ of endospores, $4.3 \times 10^{3} \mathrm{CFU} / \mathrm{g}$ of total aerobic microorganisms, and a yeast and mould con- 
tent of less than $10^{2} \mathrm{CFU} / \mathrm{g}$. The analyses of $\mathrm{CHE}$ showed values below $10^{2} \mathrm{CFU} / \mathrm{g}$ for all the microorganisms under study. The main safety hazard is the presence of ochratoxin A (OTA), a mycotoxin released by Aspergillus potentially nephrotoxic, carcinogenic, teratogenic and genotoxic. OTA limits have been defined for roasted coffee $(5 \mu \mathrm{g} / \mathrm{kg})$ and soluble coffee $(10 \mu \mathrm{g} / \mathrm{kg}$ ) [European Parlamient regulation (EC) N.123/2005, 2005]. Since CSE and CHE are extracts of two coffee by-products, there is no specific OTA regulation limit. However, the absence of moulds in these extracts reduces the risk of OTA contamination. Adding CSE and CHE to the bread formulation did not increase microorganism content, suggesting good microbiology quality of the food ingredients.

\section{Physicochemical analyses}

Data on the physicochemical characterization of CSE and CHE are shown in Table 2. Differences in the composition of CSE and CHE can be explained by their nature, as they come from different anatomic parts of the coffee fruit with different chemical components [del Castillo et al., 2019].

Total carbohydrate contents were $17.95 \mathrm{~g} / 100 \mathrm{~g}$ and $24.18 \mathrm{~g} / 100 \mathrm{~g}$ in CSE and CHE, respectively. Results obtained for CSE are in line with those reported by del Castillo et al. [2019]. As in the coffee silverskin raw material, CSE had a low content of simple sugars like glucose $(0.25 \mathrm{~g} / 100 \mathrm{~g})$, fructose $(0.83 \mathrm{~g} / 100 \mathrm{~g})$ and sucrose $(1.93 \mathrm{~g} / 100 \mathrm{~g})$. CHE had a higher glucose content $(8.88 \mathrm{~g} / 100 \mathrm{~g})$, while the contents of sucrose $(0.12 \mathrm{~g} / 100 \mathrm{~g})$ and fructose $(0.01 \mathrm{~g} / 100 \mathrm{~g})$ were lower than in CSE. Both extracts, especially CSE, presented low amounts of glycemic sugars.

The results of TDF content determination in CSE $(36.06 \mathrm{~g} / 100 \mathrm{~g})$ agree with those reported by del Castillo et al. [2019]. CSE dietary fibre is mainly composed of SDF $(27 \mathrm{~g} / 100 \mathrm{~g}$ of TDF). CHE presented a high amount of TDF $(68.43 \mathrm{~g} / 100 \mathrm{~g})$, mainly SDF (67.45 g/100 g of TDF). Both extracts can be considered good sources of SDF, especially CHE (Table 2).

The amount of soluble proteins present in CSE was $17.54 \mathrm{~g} / 100 \mathrm{~g}$ (Table 2), which is similar to the soluble protein content reported by Narita \& Inouye, 2014 for CSE obtained under subcritical water conditions. CHE had a lower soluble protein content of $5.07 \mathrm{~g} / 100 \mathrm{~g}$ close to the $7 \mathrm{~g} / 100 \mathrm{~g}$ described by Gouvea et al. [2009] for coffee husk raw material. Therefore, CSE may be a better natural source of protein than CHE.

Similarly, caffeine content was also higher in CSE (53.25 mg/g) than in CHE (13.93 mg/g) with values similar to those reported by Mesías et al. [2014] and Murthy \& Naidu [2012]. Since the safety limits of caffeine intake fixed by the European Food Safety Authority [2015] are $400 \mathrm{mg}$ per day for non-pregnant adults and $200 \mathrm{mg}$ per day for pregnant women, the daily intake of CSE considered to be safe would be $\sim 7.5 \mathrm{~g}$ for non-pregnant adults and $\sim 4 \mathrm{~g}$ for pregnant women. Consequently, the safe daily intake of $\mathrm{CHE}$ would be 4 times higher than for CSE. Caffeine content should be considered when applying these extracts for human nutrition and, in particular, considering certain members of the population.
TABLE 2. Physicochemical characterization of coffee silverskin (CSE) and coffee husk (CHE) extracts.

\begin{tabular}{|c|c|c|}
\hline Analysis & CSE & $\mathrm{CHE}$ \\
\hline Total carbohydrates (g/100 g) & $17.95 \pm 1.62^{b}$ & $24.18 \pm 1.64^{\mathrm{a}}$ \\
\hline Glucose (g/100 g) & $0.25 \pm 0.03^{b}$ & $8.88 \pm 0.10^{\mathrm{a}}$ \\
\hline Fructose $(\mathrm{g} / 100 \mathrm{~g})$ & $0.83 \pm 0.02^{\mathrm{a}}$ & $0.01 \pm 0.01^{\mathrm{b}}$ \\
\hline Sucrose (g/100 g) & $1.93 \pm 0.21^{\mathrm{a}}$ & $0.12 \pm 0.01^{\mathrm{b}}$ \\
\hline TDF $(\mathrm{g} / 100 \mathrm{~g})^{\#}$ & $36.06 \pm 1.67^{\mathrm{b}}$ & $68.43 \pm 4.50^{\mathrm{a}}$ \\
\hline $\operatorname{SDF}(\mathrm{g} / 100 \mathrm{~g}){ }^{*}$ & $27.90 \pm 1.14^{\mathrm{b}}$ & $67.45 \pm 4.65^{\mathrm{a}}$ \\
\hline $\operatorname{IDF}(\mathrm{g} / 100 \mathrm{~g})^{\#}$ & $8.17 \pm 0.53^{\mathrm{a}}$ & $0.99 \pm 0.15^{b}$ \\
\hline Total proteins (g/100 g) & $17.54 \pm 0.82^{\mathrm{a}}$ & $5.07 \pm 0.38^{\mathrm{b}}$ \\
\hline Lipids (g/100 g) & $1.83 \pm 0.58^{\mathrm{a}}$ & $1.14 \pm 0.02^{\mathrm{a}}$ \\
\hline Caffeine (mg/g) & $53.25 \pm 1.65^{\mathrm{a}}$ & $13.93 \pm 0.80^{\mathrm{b}}$ \\
\hline CGA $(\mathrm{mg} / \mathrm{g})$ & $21.30 \pm 6.17^{\mathrm{a}}$ & $1.71 \pm 0.27^{\mathrm{b}}$ \\
\hline Browning (abs/g) & $374.93 \pm 18.09^{a}$ & $58.27 \pm 3.72^{b}$ \\
\hline Melanoidins $(\mathrm{abs} / \mathrm{g})^{*}$ & $306.13 \pm 4.00^{\mathrm{a}}$ & $52.13 \pm 2.00^{b}$ \\
\hline TPC (mg CGA eq./g) & $81.03 \pm 5.56^{\mathrm{a}}$ & $19.67 \pm 1.24^{\mathrm{b}}$ \\
\hline TAC (mg CGA eq./g) & $190.86 \pm 4.25^{\mathrm{a}}$ & $52.30 \pm 0.93^{b}$ \\
\hline $\begin{array}{l}\text { Estimated calories } \\
\mathrm{kcal} / 100 \mathrm{~g} \text { extract }\end{array}$ & 158.4 & 127.3 \\
\hline$\alpha$-Glucosidase $\left(\mathrm{IC}_{50}, \mathrm{mg} / \mathrm{mL}\right)$ & $1.42 \pm 0.32^{b}$ & $2.46 \pm 0.21^{\mathrm{a}}$ \\
\hline
\end{tabular}

Data are expressed as mean $(n=3) \pm$ standard deviation. Values in each row having different letters indicate significant differences at $\mathrm{p}<0.05$ (Duncan's test). CGA, chlorogenic acid; IDF, insoluble dietary fibre; SDF, soluble dietary fibre; TAC, total antioxidant capacity; TDF, total dietary fibre; TPC, total phenolic compounds.

\#Results are expressed as mean $(n=2) \pm$ standard deviation; *Analyses performed on aqueous extracts fraction $>10 \mathrm{kDa}$.

CGA content was significantly higher in CSE $(21.30 \mathrm{mg} / \mathrm{g})$ than in CHE $(1.71 \mathrm{mg} / \mathrm{g})$. These values are lower than those described by other authors [Mesías et al., 2014; Murthy \& Naidu, 2012] but higher than those reported by Bresciani et al. [2014]. These differences might be attributed to solvent extraction, set conditions, quantification method or origin of the by-products.

Differences in browning and melanoidin were also significant between the coffee by-product extracts (Table 2). The high browning and melanoidins values of CSE are associated with the Maillard reaction occurring during the roasting process. Data on browning and melanoidins suggest that CSE may be a good source of natural colorants to be applied in the food industry. The use of natural pigments is the current marketing trend because of consumers' concern about the safety of artificial food dyes, which is reinforced by the possible health benefits of natural pigments [Rodriguez-Amaya, 2016]. In this regard, coffee melanoidins exert several beneficial effects on human health due to their antioxidant, antimicrobial, anticarcinogenic, anti-inflammatory, antihypertensive, and antiglycative properties [Moreira et al., 2012].

A TPC content of $81.03 \mathrm{mg}$ CGA eq/g was found in CSE (Table 2). This value was 4 times higher than in $\mathrm{CHE}$ 
(19.67 mg CGA eq/g). This difference in TPC content can be explained the on basis of CGA content, one of the main phenolic compounds in coffee by-products [del Castillo et al., 2019]. Similarly, TAC was 3.6 times higher in CSE than in CHE (Table 2). This great difference may be associated with their different contents of melanoidins and phenolic compounds such as CGA which has been described as the main contributor to the overall antioxidant power of coffee by-products [Mesías et al., 2014].

\section{Effects of CSE and CHE on $\alpha$-glucosidase activity}

As seen in Table 2, the $\mathrm{IC}_{50}$ values obtained for each extract were significantly different. An $\mathrm{IC}_{50}$ value of $1.42 \mathrm{mg} / \mathrm{mL}$ was obtained for CSE which is comparable to values previously described by our group [del Castillo et al., 2016]. Differences in the effect of the extracts on $\alpha$-glucosidase activity might be associated with their CGA content. This bioactive compound previously showed an $\mathrm{IC}_{50}$ value of $0.25 \mathrm{mg} / \mathrm{mL}$ [del Castillo et al., 2016]. Other authors have proposed that CGA strongly inhibits $\alpha$-glucosidase activity and reduces postprandial blood glucose [Oboh et al., 2015]. Data on the inhibitory effect on $\alpha$-glucosidase activity pinpoint CSE and CHE as ingredients to be used for better control of postprandial glucose level.

\section{Food application of CSE and CHE}

\section{Sensory analysis of innovative breads}

Breads were considered acceptable if their average score was equal to or higher than 4.0 (Figure 1). The sensory analysis indicated that the quality of NF made with inulin and rice protein was good (all values $>5.1$ ), and no significant differences were observed between NF and NFS or NFH breads. Therefore, the addition of these two coffee by-products extracts ( $25 \mathrm{~g} / \mathrm{kg} \mathrm{d} . \mathrm{m}$.) did not affect the sensory quality of the product. Comparing NFS and NFH with NF, color was the most appreciated parameter, especially for NFH. The appearance (color) of the breads containing CSE and CHE supports its feasibility as a natural colorant, providing the typical color of wholemeal breads. These results highlight the potential application of these extracts as natural colorants for gluten-free bread formulations, since the darkening of the crumb color is desirable in the consumer choice of a bread [Matos \& Rosell, 2012].

\section{Nutritional analysis of innovative breads}

Total carbohydrate content of the innovative breads (NF) and those containing CSE or CHE ( $25 \mathrm{~g} / \mathrm{kg}$ d.m.) and inulin (NFS and NFH) were significantly different from the commercial pre-mix gluten-free bread (CR) (Table 3). Fructose, glucose, and sucrose contents were significantly lower in all new bread formulations (NF, NFS and NFH). As seen in Table 1, the reduction of starch and the substitution of sugar by inulin in the innovative breads decreased glycemic carbohydrates, as described by Rizzello et al. [2016].

TDF content of NF, NFS and NFS breads was significantly higher than $\mathrm{CR}$. Adding inulin to the NF duplicated the TDF content compared to CR. CSE and CHE accounted for approximately $13 \%$ of TDF in the new bread formulations (NFS and NFH). Coffee silverskin has previously been proposed as an ingredient for reducing caloric density in biscuits
[Garcia-Serna et al., 2014]. The new bakery products could be labelled as having a "high fibre content", as they contain at least $6 \mathrm{~g}$ of fibre per $100 \mathrm{~g}$ [European Parliament Regulation [EC] N. 1924/2006 [2006]. Therefore, the use of inulin as dietary fibre improved the nutritional value of the bread.

Total protein values were significantly higher in the innovative breads (NF, NFS and NFH) compared to CR due to the addition of rice protein (Table 3). CSE provided 7\% extra protein in NFS breads compared to NF in accordance with the higher protein content of CSE (Table 2). Therefore, NF, NFS and NFH breads can be considered products that are "high in protein", containing at least 20\% of the energy value of the food provided by protein [European Parliament Regulation [EC] N. 1924/2006]. Several studies have demonstrated that the consumption of rice protein can be associated with a lower risk of oxidative stress preventing the occurrence of several diseases such as hyperlipidemia [Wang et al., 2016].

Caffeine content of NFS and NFH breads was determined to evaluate the safety of consuming these products (Table 3). The daily bread intake recommended by WHO [ 2003] for European countries is $250-350 \mathrm{~g}$. Considering the safety limits of the intake fixed by EFSA [2015], both products can be considered safe for non-pregnant adults. In the case of pregnant women, NFH consumption is safe if the daily consumption of NFS does not exceed $250 \mathrm{~g}$.

CGA content in the NFS and NFH breads supplemented with coffee by-products extracts $(25 \mathrm{~g} / \mathrm{kg} \mathrm{d}$ d.m.) degraded by $68-70 \%$ (based on initial CGA concentration in CSE and CHE) (Table 2). Other studies have also found high thermal degradation of CGA during the baking process $[\mathrm{Ru}-$ pasinghe et al., 2008]. The low sugar content in NF bread produced the highest reduction in browning compared to CR bread (Table 3). Browning values of NFS and NFH breads were higher and similar to CR, respectively. As reported in Figure 2, the addition of the extracts provided a natural color and the typical appearance of wholemeal breads. As shown in Table 3, the inclusion of extracts as food ingredients in NFS and NFH breads significantly improved

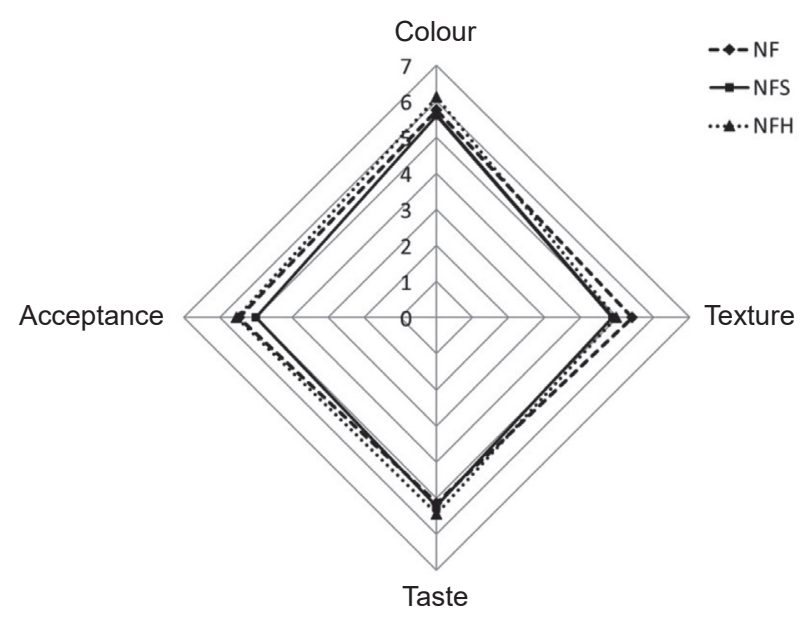

FIGURE 1. Mean scores $(n=30)$ of 1-7 scale for overall acceptance of innovative gluten-free breads NF, NFS and NFH. NF - new formulation, NFS - new formulation with $25 \mathrm{~g}$ of coffee silverskin extract (CSE)/kg d.m.; NFH - new formulation with $25 \mathrm{~g}$ of coffee husk extract (CHE)/ $\mathrm{kg} \mathrm{d.m}$. 
TABLE 3. Chemical characterization of CR, NF, NFS and NFH breads.

\begin{tabular}{|c|c|c|c|c|}
\hline Analysis & $\mathrm{CR}$ & NF & NFS & NFH \\
\hline Total carbohydrates (g/100 g) & $27.74 \pm 2.08^{\mathrm{a}}$ & $18.76 \pm 2.78^{b}$ & $18.21 \pm 1.26^{\mathrm{b}}$ & $18.38 \pm 1.40^{\mathrm{b}}$ \\
\hline Glucose $(\mathrm{g} / 100 \mathrm{~g})$ & $2.70 \pm 0.06^{\mathrm{a}}$ & $0.26 \pm 0.01^{\mathrm{c}}$ & $0.28 \pm 0.01^{\mathrm{c}}$ & $0.61 \pm 0.02^{\mathrm{b}}$ \\
\hline Fructose $(\mathrm{g} / 100 \mathrm{~g})$ & $5.10 \pm 0.06^{\mathrm{a}}$ & $1.52 \pm 0.10^{\mathrm{b}}$ & $1.53 \pm 0.02^{b}$ & $1.47 \pm 0.12^{\mathrm{b}}$ \\
\hline Sucrose $(g / 100 g)$ & $0.42 \pm 0.02^{\mathrm{a}}$ & $0.06 \pm 0.02^{\mathrm{c}}$ & $0.04 \pm 0.02^{c}$ & $0.10 \pm 0.02^{b}$ \\
\hline TDF $(g / 100 \mathrm{~g})$ & $5.73 \pm 0.91^{\mathrm{b}}$ & $11.28 \pm 0.37^{\mathrm{a}}$ & $12.72 \pm 0.52^{\mathrm{a}}$ & $12.82 \pm 1.23^{\mathrm{a}}$ \\
\hline $\operatorname{SDF}(g / 100 \mathrm{~g})$ & $4.20 \pm 0.33^{\mathrm{b}}$ & $5.90 \pm 0.20^{\mathrm{ab}}$ & $6.20 \pm 0.20^{\mathrm{ab}}$ & $6.80 \pm 0.80^{\mathrm{a}}$ \\
\hline IDF $(\mathrm{g} / 100 \mathrm{~g})$ & $1.53 \pm 0.58^{c}$ & $5.30 \pm 0.10^{b}$ & $6.50 \pm 0.30^{\mathrm{a}}$ & $6.00 \pm 0.40^{\mathrm{ab}}$ \\
\hline Total proteins $(\mathrm{g} / 100 \mathrm{~g})$ & $1.21 \pm 0.25^{\mathrm{c}}$ & $8.36 \pm 0.21^{b}$ & $9.03 \pm 0.40^{\mathrm{a}}$ & $7.36 \pm 0.98^{b}$ \\
\hline Lipids (g/100 g) & $14.89 \pm 0.47^{\mathrm{a}}$ & $2.14 \pm 0.38^{c}$ & $3.22 \pm 0.22^{b}$ & $3.30 \pm 0.31^{b}$ \\
\hline Caffeine (mg/g) & nd & nd & $0.72 \pm 0.05^{\mathrm{a}}$ & $0.36 \pm 0.02^{b}$ \\
\hline CGA (mg/g) & nd & nd & $0.25 \pm 0.01^{\mathrm{a}}$ & $0.02 \pm 0.002^{b}$ \\
\hline Browning $\left(\mathrm{Abs}_{405} / \mathrm{g}\right)$ & $1.63 \pm 0.09^{\mathrm{b}}$ & $0.90 \pm 0.05^{\mathrm{c}}$ & $2.22 \pm 0.08^{\mathrm{a}}$ & $1.21 \pm 0.02^{\mathrm{b}}$ \\
\hline Melanoidins* $\left(\mathrm{Abs}_{405} / \mathrm{g}\right)$ & $1.05 \pm 0.05^{\mathrm{b}}$ & $0.64 \pm 0.05^{\mathrm{c}}$ & $1.54 \pm 0.03^{\mathrm{a}}$ & $1.11 \pm 0.13^{\mathrm{b}}$ \\
\hline TPC (mg CGA/g) & $175.86 \pm 2.43^{\mathrm{b}}$ & $54.69 \pm 0.81^{\mathrm{d}}$ & $254.92 \pm 7.73^{\mathrm{a}}$ & $121.12 \pm 6.12^{\mathrm{c}}$ \\
\hline TAC (mg CGA/g) & $87.24 \pm 1.82^{\mathrm{c}}$ & $76.10 \pm 1.28^{\mathrm{d}}$ & $288.27 \pm 3.57^{\mathrm{a}}$ & $129.39 \pm 1.80^{\mathrm{b}}$ \\
\hline $\begin{array}{l}\text { Estimated calories } \\
(\mathrm{kcal} / 100 \mathrm{~g} \text { bread })\end{array}$ & 250 & 128 & 138 & 133 \\
\hline$\alpha$-Glucosidase $\left(\mathrm{IC}_{50,} \mathrm{mg} / \mathrm{mL}\right)$ & $38.10 \pm 2.10^{\mathrm{b}}$ & $108.60 \pm 1.76^{\mathrm{a}}$ & $27.00 \pm 1.95^{\mathrm{d}}$ & $32.70 \pm 2.56^{\mathrm{c}}$ \\
\hline
\end{tabular}

$\mathrm{CR}$ - commercial recipe; NF - new formulation; NFS - new formulation with $25 \mathrm{~g}$ of coffee silverskin extract (CSE)/kg d.m.; NFH - new formulation with $25 \mathrm{~g}$ of coffee husk extract (CHE)/ $\mathrm{kg}$ d.m.

Data are expressed as mean $(n=3) \pm$ standard deviation. Values in each row having different letters indicate significant differences at $\mathrm{p}<0.05$ (Duncan's test). CGA, chlorogenic acid; IDF, insoluble dietary fibre; nd, not detected; SDF, soluble dietary fibre; TAC, total antioxidant capacity; TDF, total dietary fibre; TPC, total phenolic compounds. *Analyses performed on aqueous extracts fraction $>10 \mathrm{kDa}$.

antioxidant capacity (3.78 and 1.70-times higher compared to NF control bread for NFS and NFH breads, respectively). This higher antioxidant capacity could be related to phenolic compounds such as CGA and melanoidins. Antioxidants can play a double role as food preservatives and health-promoting compounds.

The highest TPC content was found in NFS bread (Table 3). Differences in TPC may be due to bread composition. $\mathrm{CR}$ bread had highest content of gluten-free baking pre-mix (Table 1) which had corn flour. Soong et al. [2014] have reported that baked muffins made with corn flour had a higher TPC content than those baked with rice flours. Consequently, NF had the lowest TPC content which increased to $79 \%$ and 55\% with the addition of CSE and CHE, respectively. These results are in line with TPC values shown by CSE and CHE (Table 2).

\section{Effect of bread components on $\alpha$-glucosidase activity}

As seen in Table 3, the addition of CSE and CHE to NF inhibited $\alpha$-glucosidase activity in accordance with the results obtained for CSE and CHE ingredients (Table 2). The inhibitory activity of CSE was related to the presence of CGA [del Castillo et al., 2016]. $\mathrm{IC}_{50}$ values of NFS $(27.00 \mathrm{mg} / \mathrm{mL})$ and NFH $(32.70 \mathrm{mg} / \mathrm{mL})$ breads are comparable to those reported for similar products such as pasta enriched with faba bean flour [Turco et al., 2016].

\section{Bioaccessibility of nutrients and bioactive compounds composing the innovative breads}

As reported in Table 4, substituting the sugar and starch of the gluten-free baking pre-mix with inulin significantly reduced glycemic sugar content in digested NF, NFS and NFH compared to CR. Total glucose and fructose content was by at least 35\% lower in NFH and NFS. A low content of free glucose available for absorption is an important factor in the prevention of diabetes.

CGA was not detected in NFS and NFH digested breads (Table 4). Previous studies have reported a significant decrease in CGA concentration during CSE digestion, especially after the hydrolysis reaction of the duodenal step [Fernandez-Gomez et al., 2016]. Part of the CGA could be linked to the maillardized dietary coffee fibre structure which could protect against oxidative damages in the large intestine. The inclusion of phenolic groups, especially CGA, in the coffee melanoidin skeleton has been reported [Moreira et al., 2012].

The antioxidant capacity of digested fractions of NFS and NFH breads was significantly higher than CR but was 


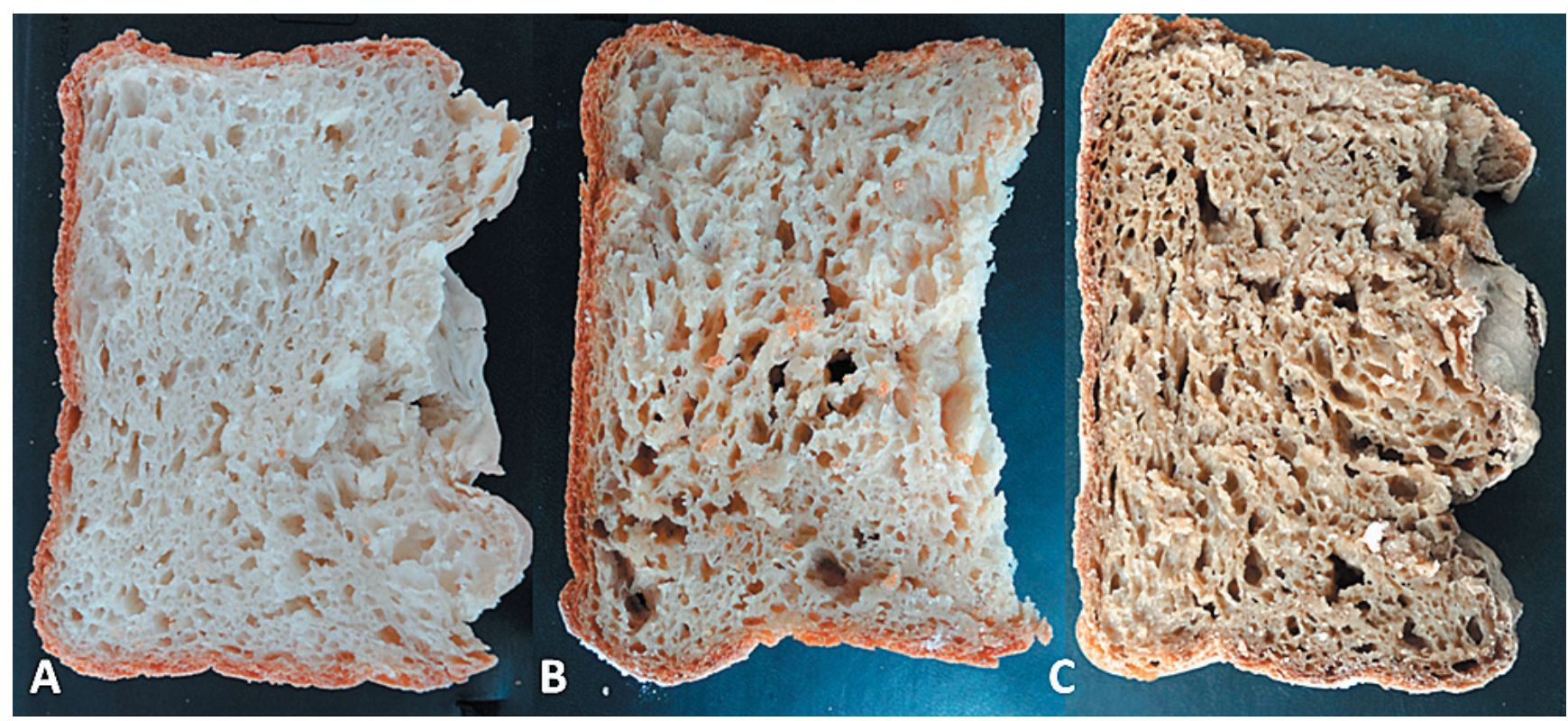

FIGURE 2. Cross section of innovative breads: (A) NF - new formulation, (B) NFS - new formulation with $25 \mathrm{~g}$ of coffee silverskin extract (CSE)/kg d.m.; (C) NFH - new formulation with $25 \mathrm{~g}$ of coffee husk extract (CHE)/ $\mathrm{kg}$ d.m.

similar to NF. This might be related to the release of several peptides with antioxidant properties caused by the hydrolysis of the rice protein during the digestion process. The rice protein used in this study is enriched in sulfur-amino acids which exert an antioxidative effect by scavenging free radicals [Métayer et al., 2008].

As seen in Table 4, the antioxidant capacity of the insoluble fraction recovered from the digestion process of NFS and NFH breads was significantly higher than that found for
NF samples. Maillardized dietary coffee fibre may be responsible for the higher antioxidant power of the non-bioaccessible fraction [Silván et al., 2010].

No significant differences were found among the $\mathrm{IC}_{50}$ values of the bioaccessible fractions of the digested breads (Table 4). The reduced inhibitory effect may be associated with the loss of free CGA during the digestion process. CGA inhibited $\alpha$-glucosidase activity in a dose-dependent manner [Oboh et al., 2015].

TABLE 4. Chemical characterization of CR, NF, NFS and NFH digested breads.

\begin{tabular}{|c|c|c|c|c|}
\hline Analysis & $\mathrm{CR}$ & NF & NFS & NFH \\
\hline \multicolumn{5}{|c|}{ Soluble fraction } \\
\hline Glucose (g/100 g) & $7.47 \pm 0.13^{\mathrm{a}}$ & $7.05 \pm 0.19^{\mathrm{b}}$ & $5.86 \pm 0.08^{\mathrm{c}}$ & $5.72 \pm 0.28^{c}$ \\
\hline Fructose $(\mathrm{g} / 100 \mathrm{~g})$ & $3.42 \pm 0.11^{\mathrm{a}}$ & $3.37 \pm 0.08^{\mathrm{a}}$ & $1.15 \pm 0.01^{\mathrm{c}}$ & $1.58 \pm 0.10^{\mathrm{b}}$ \\
\hline Sucrose $(g / 100 g)$ & $0.42 \pm 0.02$ & nd & nd & nd \\
\hline FAG (mg lys eq/1000 g) & $0.20 \pm 0.01^{\mathrm{b}}$ & $0.26 \pm 0.07^{\mathrm{b}}$ & $0.33 \pm 0.12^{\mathrm{ab}}$ & $0.45 \pm 0.05^{\mathrm{a}}$ \\
\hline Caffeine (mg/g) & nd & nd & $0.43 \pm 0.01^{\mathrm{a}}$ & $0.17 \pm 0.02^{\mathrm{b}}$ \\
\hline CGA (mg/g) & nd & nd & nd & nd \\
\hline TPC (mg CGA/g) & $134.86 \pm 6.05^{\mathrm{c}}$ & $227.92 \pm 17.56^{\mathrm{b}}$ & $265.70 \pm 18.02^{\mathrm{a}}$ & $222.18 \pm 7.89^{b}$ \\
\hline TAC-I (mg CGA eq/g) & $573.96 \pm 30.70^{b}$ & $742.62 \pm 23.55^{\mathrm{a}}$ & $756.29 \pm 22.76^{\mathrm{a}}$ & $721.34 \pm 27.86^{\mathrm{a}}$ \\
\hline$\alpha$-Glucosidase $\left(\mathrm{IC}_{50}, \mathrm{mg} / \mathrm{mL}\right)$ & $5.40 \pm 0.85^{\mathrm{a}}$ & $5.20 \pm 1.20^{\mathrm{a}}$ & $5.20 \pm 0.87^{\mathrm{a}}$ & $5.90 \pm 1.45^{\mathrm{a}}$ \\
\hline \multicolumn{5}{|c|}{ Insoluble fraction } \\
\hline TAC-D (g CGA eq/100 g) & nd & $22.88 \pm 2.80^{\mathrm{c}}$ & $35.01 \pm 0.97^{\mathrm{a}}$ & $30.68 \pm 0.94^{b}$ \\
\hline
\end{tabular}

$\mathrm{CR}$ - commercial recipe; NF - new formulation; NFS - new formulation with $25 \mathrm{~g}$ of coffee silverskin extract (CSE)/kg d.m.; NFH - new formulation with $25 \mathrm{~g}$ of coffee husk extract (CHE)/ kg d.m.

Data are expressed as mean $(n=3) \pm$ standard deviation. Values in each row having different letters indicate significant differences at $\mathrm{p}<0.05$ (Duncan's test). CGA, chlorogenic acid; nd, not detected; FAG, free amino groups; TAC-D, total antioxidant capacity direct method; TAC-I, total antioxidant capacity indirect method; TPC, total phenolic compounds. 


\section{CONCLUSIONS}

CSE and CHE are sustainable natural sources of antioxidants and $\alpha$-glucosidase inhibitors. Furthermore, the extracts can be employed as natural colorants in the high dietary content formulation to provide the typical appearance of wholemeal bread. The new gluten-free bread formulations developed during this study may provide additional health benefits in people with specific nutritional requirements. Proof-of-concept human intervention studies are needed to verify the positive effects of these breads in controlling postprandial glucose. In conclusion, the nutritional properties of the new gluten-free bread formulations were greatly improved compared to the gluten-free commercial breads.

\section{ACKNOWLEDGEMENTS}

We would like to thank Beneo Ibérica (Spain) for supplying Inulin (ORAFTI ${ }^{\circledR}$ FTX) and rice protein (Remypro $\mathrm{N} 80+$ ), and Fortaleza (Vitoria) and Delikia (Valencia) for supplying coffee silverskin and coffee husks, respectively.

\section{RESEARCH FUNDING}

The present research was funded by the project SUSCOFFEE (AGL2014-57239-R) and is part of the PhD. thesis of Guglielmetti, A.

\section{REFERENCES}

1. Açar, Ö.Ç., Gökmen, V., Pellegrini, N., Fogliano, V. (2009). Direct evaluation of the total antioxidant capacity of raw and roasted pulses, nuts and seeds. European Food Research and Technology, 229(6), 961-969.

2. AACC Method 32-07. Determination of Soluble, Insoluble and Total Dietary Fiber in Foods and Food Products. Approved Methods of the American Association of Cereal Chemists, 9th ed. The Association, St. Paul, MN, 1995.

3. AOAC Method 991.43. Total, Insoluble and Soluble Dietary Fiber in Food-Enzymatic Gravimetric Method, MES-TRIS Buffer. Official Methods of Analysis, 16th ed. AOAC International, Gaithersburg, MD, 1995.

4. AOAC No. 32.1.22. Oficial method 920.87. Protein (total) in flour, Final Action. In: Cunniff, P. (ed.): Official methods of analysis of AOAC International. 16th ed. Arlington, Virginia : AOAC International, 1995, p. 12

5. Ballesteros, L.F., Teixeira, J.A., Mussatto, S.I. (2014). Chemical, functional, and structural properties of spent coffee grounds and coffee silverskin. Food Bioprocessing Technology, 7(12), 3493-3503.

6. Berthelot, K., Delmotte, F.M. (1999). Purification and characterization of an alpha-glucosidase from Rhizobium sp. (Robinia pseudoacacia L.) strain USDA 4280. Applied and Environmental Microbiology, 65(7), 2907-2911.

7. Bresciani, L., Calani, L., Bruni, R., Brighenti, F., Del Rio, D. (2014). Phenolic composition, caffeine content and antioxidant capacity of coffee silverskin. Food Research International, 61, SI, 196-201.
8. Conte, P., Fadda, C., Drabińska, N., Krupa-Kozak, U. (2019). Technological and nutritional challenges, and novelty in glutenfree breadmaking: a review. Polish Journal of Food and Nutrition Sciences, 69(1), 5-21.

9. Contini, M., Baccelloni, S., Massantini, R., Anelli, G. (2008). Extraction of natural antioxidants from hazelnut (Corylus avellana L.) shell and skin wastes by long maceration at room temperature. Food Chemistry, 110(3), 659-669.

10. del Castillo, M.D., Ibáñez, ME, Amigo, M., Herrero, M., Plaza del Moral, M., Ullate, M. (2013). Aplication of products of coffee silverskin in anti-ageing cosmetics and functional food. Patent no. WO 2013/004873.

11. del Castillo, M.D., Fernandez-Gomez, B., Ullate, M., Mesa, M.D. (2014). Use of coffee husk products for the prevention and treatment of the pathologies that make up the metabolic syndrome ad its metabolic factors risk. Patent no. P201431848.

12. del Castillo, M.D., Fernandez-Gomez, B., Martinez-Saez, N., Iriondo-DeHond, A., Martirosyan, D.M., Mesa, M.D. (2016). Coffee silverskin extract for aging and chronic diseases. In D.M. Martirosyan (Ed.), Functional Foods In Health And Disease, First ed., San Diego: Functional Food Center Inc., pp. 389-409.

13. del Castillo, M.D., Fernandez-Gomez, B., Martinez-Saez, N., Iriondo-DeHond, A., Mesa, M.D. (2019). Coffee By-Products. In A. Farah (Ed.), Coffee: Chemistry, Quality and Health Implications, First ed., RSC Publishing Inc., pp.309-334.

14. EFSA, Scientific Opinion on the Safety of Caffeine. (2015). EFSA Journal, 13(5), 4102.

15. European Parliament Regulation (EC) N. 1924/2006. (2006). On nutrition and health claims made on foods. Official Journal of the European Union.

16. European Parliament Regulation (EC) 123/2005. (2005). As regards Ochratoxin. Official Journal of the European Union.

17. Fernandez-Gomez, B., Lezama, A., Amigo-Benavent, M., Ullate, M., Herrero, M., Martín, M.A., Mesa, M.D., del Castillo, M.D. (2016). Insights on the health benefits of the bioactive compounds of coffee silverskin extract. Journal of Functional Foods, 25, 197-207.

18. Garcia-Serna, E., Martinez-Saez, N., Mesias, M., Morales, F.J., Castillo, M.D. del. (2014). Use of coffee silverskin and stevia to improve the formulation of biscuits. Polish Journal of Food and Nutrition Sciences, 64(4), 243-251.

19. Giuberti, G., Gallo, A., Cerioli, C., Fortunati, P., Masoero, F. (2015). Cooking quality and starch digestibility of gluten free pasta using new bean flour. Food Chemistry, 175, 43-49.

20. Gouvea, B. M., Torres, C., Franca, A.S., Oliveira, L.S., Oliveira, E.S. (2009). Feasibility of ethanol production from coffee husks. Biotechnology Letters, 31 (9), SI, 1315-1319.

21. Hollebeeck, S., Borlon, F., Schneider, Y.J., Larondelle, Y., Rogez, H. (2013). Development of a standardised human in vitro digestion protocol based on macronutrient digestion using response surface methodology. Food Chemistry, 138(2-3), 1936-1944.

22. Iriondo-DeHond, A., Aparicio García, N., Fernández-Gomez, B., Guisantes-Batán, E., Velazquez Escobar, F., San Andres, M.I., Sanchez-Fortun, S., Blanch, G.P., del Castillo, M.D. (2018). Validation of coffee by-products as novel food ingredients. Innovative Food Science and Emerging Technologies, 51, 194-204.

23. Martinez-Saez, N., García, A.T., Pérez, I.D., Rebollo-Hernanz, M., Mesías, M., Morales, F.J., del Castillo, M.D. (2017). Use 
of spent coffee grounds as food ingredient in bakery products. Food Chemistry, 216, 114-122.

24. Masuko, T., Minami, A., Iwasaki, N., Majima, T., Nishimura, S.I., Lee, Y.C. (2005). Carbohydrate analysis by a phenol-sulfuric acid method in microplate format. Analytical Biochemistry, 339(1), 69-72.

25. Matos, M.E., Rosell, C.M. (2012). Relationship between instrumental parameters and sensory characteristics in gluten-free breads. European Food Research and Technology, 235(1), 107-117.

26. Mesías, M., Navarro, M., Martínez-Saez, N., Ullate, M., del Castillo, M.D., Morales, F.J. (2014). Antiglycative and carbonyl trapping properties of the water soluble fraction of coffee silverskin. Food Research International, 62, 1120-1126.

27. Métayer, S., Seiliez, I., Collin, A., Duchêne, S., Mercier, Y., Geraert, P.A., Tesseraud, S. (2008). Mechanisms through which sulfur amino acids control protein metabolism and oxidative status. The Journal of Nutritional Biochemistry, 19(4), 207-215.

28. Michalska, A., Amigo-Benavent, M., Zielinski, H., del Castillo, M.D. (2008). Effect of bread making on formation of Maillard reaction products contributing to the overall antioxidant activity of rye bread. Journal of Cereal Science, 48(1), 123-132.

29. Moreira, A.S.P., Nunes, F.M., Domingues, M.R., Coimbra, M.A. (2012). Coffee melanoidins: structures, mechanisms of formation and potential health impacts. Food \& Function, 3(9), 903-915.

30. Murthy, P.S., Madhava Naidu, M. (2012). Sustainable management of coffee industry by-products and value addition - A review. Resources, Conservation and Recycling, 66, 45-58.

31. Narita, Y., Inouye, K. (2014). Review on utilization and composition of coffee silverskin. Food Research International, 61, SI, 16-22.

32. Oboh, G., Agunloye, O.M., Adefegha, S.A., Akinyemi, A.J., Ademiluyi, A.O. (2015). Caffeic and chlorogenic acids inhibit key enzymes linked to type 2 diabetes (in vitro): a comparative study. Journal of Basic and Clinical Physiology and Pharmacology, 26(2), 165-170.

33. Oki, T., Nagai, S., Yoshinaga, M., Nishiba, Y., Suda, I. (2006). Contribution of beta-carotene to radical scavenging capacity varies among orange-fleshed sweet potato cultivars. Food Science and Technology Research, 12(2), 156-160.

34. Padalino, L., Conte, A., Del Nobile, M.A. (2016). Overview on the general approaches to improve gluten-free pasta and bread. Foods (Basel, Switzerland), 5(4), art. no. 87.
35. Pourfarzad, A., Mahdavian-Mehr, H., Sedaghat, N. (2013). Coffee silverskin as a source of dietary fiber in bread-making: Optimization of chemical treatment using response surface methodology. LWT - Food Science and Technology, 50(2), 599-606.

36. Rizzello, C.G., Montemurro, M., Gobbetti, M. (2016). Characterization of the bread made with durum wheat semolina rendered gluten free by sourdough biotechnology in comparison with commercial gluten-free products. Journal of Food Science, 81 (9), H2263-H2272.

37. Rodriguez-Amaya, D.B. (2016). Natural food pigments and colorants. Current Opinion in Food Science, 7, 20-26.

38. Rupasinghe Vasantha, H.P., Wang, L., Huber, G.M., Pitts, N.L. (2008). Effect of baking on dietary fibre and phenolics of muffins incorporated with apple skin powder. Food Chemistry, 107(3), $1217-1224$.

39. Scazzina, F., Dall'Asta, M., Pellegrini, N., Brighenti, F. (2015). Glycaemic index of some commercial gluten-free foods. European Journal of Nutrition, 54(6), 1021-1026.

40. Silván, J.M., Morales, F.J., Saura-Calixto, F. (2010). Conceptual study on maillardized dietary fiber in coffee. Journal of Agricultural and Food Chemistry, 58(23), 12244-9.

41. Soong, Y.Y., Tan, S.P., Leong, L.P., Henry, J.K. (2014). Total antioxidant capacity and starch digestibility of muffins baked with rice, wheat, oat, corn and barley flour. Food Chemistry, 164, 462-469.

42. Toschi, T.G., Cardenia, V., Bonaga, G., Mandrioli, M., Rodriguez-estrada, M.T. (2014). Coffee Silverskin : characterization, possible uses, and safety aspects. Journal of Agricultural and Food Chemistry, 62(44), 10836-10844.

43. Turco, I., Bacchetti, T., Bender, C., Zimmermann, B., Oboh, G., Ferretti, G. (2016). Polyphenol content and glycemic load of pasta enriched with faba bean flour. Functional Foods in Health and Disease, 6(5), 291-305.

44. Wang, Z., Liu, Y., Li, H., Yang, L. (2016). Rice proteins, extracted by alkali and $\alpha$-amylase, differently affect in vitro antioxidant activity. Food Chemistry, 206, 137-45.

45. WHO. (2003). Food based dietary guidelines in the WHO European Region.

Submitted: 27 November 2018. Revised: 28 January 2019. Accepted: 8 February 2019. Published on-line: 29 March 2019. 